\title{
Dietary Diversity Practice and Associated Factors Among Infants and Young Children in Haramaya Town, Ethiopia
}

\author{
Berhe Gebremichael ${ }^{1}$, Gudina Egata ${ }^{2}$, Nega Assefa ${ }^{3}$ \\ ${ }^{1,2}$ School of Public Health, College of Health and Medical Sciences, Haramaya University, Ethiopia \\ ${ }^{3}$ School of Nursing and Midwifery, College of Health and Medical Sciences, Haramaya University, Ethiopia
}

\begin{abstract}
Article Info
Article history:

Received Jun 13, 2017

Revised Aug 102017

Accepted Aug 26, 2017

\section{Keyword:}

Dietary diversity

Ethiopia

Haramaya

Infants

Young children

ABSTRACT

Optimum child feeding is crucial for growth, development, and better health in later life. Dietary diversity is a critical part of the feeding practices. However, there is limited evidence on dietary diversity practice in lowincome countries, like Ethiopia. This study assessed dietary diversity practice and associated factors among mothers of infants and young children aged 6-23 months in Haramaya Town, Eastern Ethiopia. Community based cross-sectional study design was used and study participants were selected by simple random sampling. Data were collected using a pre-tested questionnaire by face-to-face interview. The collected data were entered to EpiData version 3.1 and exported to SPSS version 22.0 for analysis. Characteristics of the study participants were described by using frequencies, percentages, summary measures, and tables. Bi-variable and multi-variable analyses were used to identify the associated factors. Statistical significance was declared at $\mathrm{p}$-value $<0.05$. The study included 635 participants yielding to a response rate of $98.1 \%$. The prevalence of dietary diversity practice was $25.2 \%$. Mothers learned up to secondary level or above [(AOR $=2.97,95 \%$ CI: $(1.26,6.99)]$, mothers who had job [(AOR=3.21, 95\% CI: $(1.41,7.29)]$, older children [(AOR=2.51, 95\% CI: $(1.45,4.34)]$, male children [(AOR= 2.08, 95\% CI: $(1.29,3.33)]$, healthy children [(AOR=2.65, 95\% CI: 1.36 , 5.16)] and richest households [( $\mathrm{AOR}=4.45,95 \% \mathrm{CI}: 1.94,10.22)]$ were associated with dietary diversity practice. Generally, the dietary diversity practice was low. Therefore, attention should be given to mothers with no formal education and efforts should be done to improve the socioeconomic status of the households.
\end{abstract}

Copyright (C) 2017 Institute of Advanced Engineering and Science. All rights reserved.

Corresponding Author:

Berhe Gebremichael,

School of Public Health, College of Health and Medical Sciences,

Haramaya University, Ethiopia.

Email: berhegere09@gmail.com

\section{INTRODUCTION}

Adequate nutrition is important during the first two years of life to improve the survival, growth, and development outcomes of children [1],[2]. The first 1000 days (conception to 24 months of life) are the critical window of opportunity for improving child nutrition. Exclusive breastfeeding and adequate complementary feeding can prevent $13 \%$ and $6 \%$ of the annual under five children mortality, respectively. But only about two-fifths and two-thirds of infants worldwide are exclusively breastfed and appropriately introduced to solid foods, respectively [2],[3]. Improving the quality of complementary food, which can be ensured by dietary diversity, has been cited as one of the cost effective strategies for improving health, reducing morbidity and mortality of young children [4].

Globally, 6.9 million under-five children died in 2011, and more than one-third of these deaths were related to under-nutrition [5]. In developing countries, under-nutrition accounts for $45 \%$ of under five 
children mortality [6],[7]. Currently, poor infant and young child feeding practice is identified as a significant contributor to under-nutrition worldwide [8],[9] and interventions to improve feeding practices are among the globally recommended core packages of direct nutrition interventions [10],[11]. Asian and African countries have more severe burden of under-nutrition and poor feeding practices, where less than one-third of 6-23 months old children meet the minimum standard for dietary diversity [3],[9].

Ethiopia is also affected by under-nutrition and poor feeding practices, where one-fifth of all infant deaths are attributed to poor feeding practices [12]. One out of twenty children achieved the minimum standard for dietary diversity according to Ethiopian demographic and health survey (2011) [13]. Other pocket studies in the northern and southern parts of the country showed minimum dietary diversity was 8.5\%-39\% [14]-[18]. Most of the studies done on complementary feeding practice in Ethiopia mainly focused on the time of introduction of complementary feeding, which is one component of complementary feeding practice. Studies on dietary diversity, another component of complementary feeding, in urban settings were previously reported from the northern part of the country [14],[18]. However, the practice and the associated factors of dietary diversity vary from area to area. Therefore, there is a need to study the prevalence of dietary diversity and its associated factors among mothers of infants and young children aged 6-23 months in Eastern Ethiopia to provide information that is context-specific to allow for appropriate interventions.

\section{RESEARCH METHOD}

A community based cross-sectional study design was applied to interview mothers having infants and young children aged 6-23 months in Haramaya Town of Eastern Ethiopia from February 20 to March 04/2016. Haramaya town is the administrative center of Haramaya District in the Eastern Ethiopia, which has a total population of 42,815; of whom, 1,674 (3.91\%) and 9,475 (22.13\%) of them are infants/children aged 6-23 months and women of reproductive age group, respectively. The town is located $506 \mathrm{~km}$ to the east of the capital, Addis Ababa, on the way to Harar Town.

The sample size for the prevalence of dietary diversity practice was determined by single population proportion formula $\left.\left(\mathrm{n}=\left(\mathrm{Z}_{\alpha / 2}\right)^{2} \mathrm{pq} / \mathrm{d}^{2}\right)\right)$, considering confidence level at $95 \%=1.96$, margin of error $=0.04$ and $\mathrm{p}=0.51$ from previous study done in Ghana [19], which resulted in a sample of 600. The sample size for the associated factors was calculated by double population proportion formula on Epi Info version 7 assuming confidence level $=95 \%$, power $=80 \%$ and the ratio of unexposed to exposed $=1$. Among the factors, maternal media exposure from a study done in northern Ethiopia [14] provided the highest sample size (i.e. 616). Finally, sample size was fixed at 647 by adding $5 \%$ on 616 for non-response.

The simple random sampling technique was used to select study participants after constructing the sampling frame of 1674 infant/children. The sampling frame was constructed based on a unique identification number assigned for each infant/child obtained from health extension workers of the town. Finally, 647 infants/children were randomly selected on SPSS version 22.0. Mothers of infants and young children aged 6-23 months who lived for a minimum of 6 months in the town were included in the study, whereas mothers who were seriously sick, had a mental health problem or else that made communication difficult to get the necessary data were not included.

The study used an interviewer-administered questionnaire after the questionnaire was pre-tested and translated into the local languages (Amharic and Afan Oromo). The data collection tool for dietary diversity practice was adopted from World Health Organization (WHO) standardized questionnaire for Infant and Young Child Feeding (IYCF) practices [20]. It was based on mother's recall of foods given to her child in the past 24 hours prior to the interview. A data collection tool for household food security was adopted from Food and Nutrition Technical Assistance [4] standardized questionnaire, which are based on four weeks recall method. In addition to this, another data collection tool for household assets/properties was adopted from Ethiopian Demographic and Health Survey of 2011 [13].

The data collectors were ten students who completed grade 10 and above, and the supervisors were two diploma nurses. They were trained for two days on the data collection tools and data collection procedure. The data collectors were organized into five pairs to minimize errors during data collection and they were closely supervised by supervisors. Data were collected on socio-demographic and economic characteristics of the respondents, health care service utilization, social influences to mothers on child feeding, and maternal knowledge and practice on dietary diversity. The data were collected by going through home-to-home visit from each mother of infants and young children in a period of 15 days.

The dependent variable, dietary diversity practice, was measured by minimum dietary diversity. Minimum dietary diversity is achieved (practiced) if an infant/child aged 6-23 months received foods from 4 or more varieties of food groups out of 7 food groups per 24 hours. The 7 food groups are grains/roots/tubers, legumes/nuts, dairy products (milk, yogurt and cheese), flesh foods (meat, fish, poultry and liver/organ meats), eggs, vitamin-A rich fruits and vegetables, and other fruits and vegetables [4]. 
Maternal knowledge on dietary diversity was measured by developing seven knowledge related questions based on the seven food groups that should be consumed by infants/children. The response of each question was coded as "1" for "yes" and "0" for "no." Then total score was calculated for each mother. Finally, mothers with mean score, which was 3.5, and above were considered as having 'good knowledge' and those with less than the mean score were considered as having 'poor knowledge.'

After data collection, each questionnaire was checked for completeness and consistency by supervisors. Then the data were coded, entered, and cleaned using EpiData version 3.1 and exported to SPSS version 22 for analysis. Descriptive statistics were described and presented using frequencies, percentages, summary measures, and tables. Household food security was analyzed using Household Food Insecurity Access Scale (HFIAS). Household wealth index was constructed by using Principal Component Analysis (PCA). Bi-variable logistic regression analysis was used to see the association between each independent and the outcome variables. Variables with $\mathrm{p}$-value $\leq 0.25$ were included into multivariable logistic regression analysis model. Then the multi-variable analysis was done to control the confounding factors. Adjusted Odds Ratio (AOR) with 95\% CI was estimated to identify factors associated with dietary diversity practice. Finally, statistical significance was declared at p-value $<0.05$.

Ethical clearance was secured from Institutional Health Research Ethics Review Committee of the College of Health and Medical Sciences, Haramaya University. A formal letter of cooperation was written for Haramaya Town Health Office. Informed consent was obtained from each mother of the infants and young children. The interview was carrying out privately in a separate room. Names or personal identifiers were not included in the questionnaires in order to ensure participants' confidentiality.

\section{RESULTS AND ANALYSIS}

\subsection{Socio-demographic and economic characteristics}

A total of 635 mothers of infants and young children aged 6-23 months were included in this study yielding to a response rate of $98.1 \%$. The median age of the mothers was 28 years with inter-quartile range of 8 years. About $584(92.1 \%)$ and $422(66.5 \%)$ of the mothers were married and attended formal education, respectively. The majority of, $487(76.7 \%)$, the mothers were working during one year prior to the study and $452(71.2 \%)$ were Muslim in religion. Out of 584 married mothers, $443(75.9 \%)$ and $175(30 \%)$ of their husbands had formal education and were merchants, respectively.

Regarding to the infant/child characteristics, 329 (51.8\%) of them were males and their mean ( \pm SD) age was $14.8 \pm 5.4$ years. About $199(31.3 \%)$ of them were first born and the birth interval with their preceding sibling was $\geq 24$ months in $274(62.8 \%)$ of the children. Regarding to the health status of the children, $172(27.1 \%)$ out of 634 were sick during the last two weeks prior to the study, of whom fever with chills, $53(30.8 \%)$, and diarrhea, 52 (30.2\%), were the major complaints.

The average $( \pm \mathrm{SD})$ family size of the respondents was $4.7 \pm 1.8$ and the median number of under-five children was 2 which range from 1 to 6 . Decision on child feeding was made by mothers in $590(92.9 \%)$ of the 635 respondents. The majority of, 469 (74\%), the households obtain their food from purchasing and 386 $(60.8 \%)$ of them were food secured (Table 1$)$.

\subsection{Health care service use characteristics}

Out of 633 mothers, $559(88.3 \%)$ had antenatal care follow up when they were pregnant for the index child. Among the mothers who had antenatal care follow up, 168 (26.5\%) of them had 1-3 visits and $391(61 \%)$ had four or more visits. Besides of this, $575(90.6 \%)$ out of 635 mothers delivered their child at health facilities and the rest $53(8.3 \%)$ and seven of them delivered at home and other places, respectively. About $548(86.6 \%)$ of the deliveries for the index children were attended by health professionals. Regarding to post natal care, $307(48.3 \%), 185(29.1 \%), 57(9.0 \%)$ and $86(13.5 \%)$ of the mothers had three or above visits, two visits, one visit and no visit for the index child, respectively. Concerning to child growth monitoring and vaccination, $562(88.5 \%)$ and $540(85 \%)$ of the children had gone growth monitoring and were vaccinated, respectively.

\subsection{Maternal knowledge of dietary diversity practice}

Out of 633 mothers, $594(93.8 \%)$ of them had heard about complementary feeding. The main sources of information were health professionals in about $565(95.1 \%)$ of the respondents, followed by neighbors and peers in $14(2.4 \%)$ and nine of the respondents, respectively. About $582(91.8 \%)$ out of 634 mothers responded that dietary diversity is essential for infants and young children, but $216(34.1 \%)$ of the mothers had good knowledge ( $\geq$ mean score) on dietary diversity of their children (Table 2). Most of the mothers, $555(87.5 \%)$ had good knowledge on grains, roots and tubers. 
Table 1. Socio-demographic and Economic Characteristics of Respondents

\begin{tabular}{|c|c|c|c|}
\hline \multicolumn{2}{|c|}{ Variables } & \multirow{2}{*}{$\begin{array}{c}\text { Frequency } \\
140\end{array}$} & \multirow{2}{*}{$\begin{array}{c}\text { Percentage } \\
22.1\end{array}$} \\
\hline Maternal level of education $(n=635)$ & Unable to read and write & & \\
\hline & Able to read and write & 73 & 11.5 \\
\hline & Primary level & 174 & 27.4 \\
\hline & Secondary level & 110 & 17.3 \\
\hline & College and above & 138 & 21.7 \\
\hline \multirow[t]{4}{*}{ Maternal marital status $(n=634)$} & Single & 15 & 2.4 \\
\hline & Married/partner & 584 & 92.1 \\
\hline & Divorced/separated & 23 & 3.6 \\
\hline & Widowed & 12 & 1.9 \\
\hline \multirow[t]{5}{*}{ Father educational status $(n=584)$} & Unable to read and write & 68 & 11.6 \\
\hline & Able to read and write & 73 & 12.5 \\
\hline & Primary level & 135 & 23.1 \\
\hline & Secondary level & 123 & 21.1 \\
\hline & College and above & 185 & 31.7 \\
\hline \multirow[t]{5}{*}{ Father's occupation $(\mathrm{n}=584)$} & Farmer & 118 & 20.2 \\
\hline & Merchant & 175 & 30.0 \\
\hline & Government employee & 135 & 23.1 \\
\hline & Non-governmental employee & 38 & 6.5 \\
\hline & Daily laborer & 118 & 20.2 \\
\hline \multirow[t]{3}{*}{ Maternal religion $(n=633)$} & Muslim & 452 & 71.4 \\
\hline & Orthodox & 137 & 21.6 \\
\hline & Protestant & 44 & 7.0 \\
\hline \multirow[t]{3}{*}{ Child age group (in months) $(n=635)$} & $6-11$ & 206 & 32.4 \\
\hline & $12-17$ & 187 & 29.4 \\
\hline & $18-23$ & 242 & 38.2 \\
\hline \multirow[t]{4}{*}{ Birth order $(n=635)$} & First & 199 & 31.3 \\
\hline & Second & 161 & 25.3 \\
\hline & Third & 107 & 16.9 \\
\hline & Fourth and above & 168 & 26.5 \\
\hline Child health complaints (during 2 weeks & Diarrhea & 52 & 30.2 \\
\hline \multirow[t]{4}{*}{ prior to the study) $(\mathrm{n}=172)$} & Vomiting & 20 & 11.6 \\
\hline & Fever with chills & 53 & 30.8 \\
\hline & Fever with cough and difficulty of breathing & 43 & 25.0 \\
\hline & Accident & 4 & \\
\hline \multirow[t]{3}{*}{ Household food source $(n=635)$} & Purchasing & 469 & 74.0 \\
\hline & Own production & 159 & 25.0 \\
\hline & Aid/donation & 7 & \\
\hline \multirow[t]{4}{*}{ Household food security status $(\mathrm{n}=635)$} & Secured & 386 & 60.8 \\
\hline & Mildly insecure & 39 & 6.1 \\
\hline & Moderately insecure & 89 & 14 \\
\hline & Severely insecure & 121 & 19.1 \\
\hline
\end{tabular}

Table 2. Knowledge on Dietary Diversity Among Mothers of Infants and Young Children Aged 6-23 in Haramaya Town of Eastern Ethiopia

\begin{tabular}{lcc}
\hline \multicolumn{1}{c}{ Food Group } & Frequency & Percentage \\
\hline Good knowledge on grains, roots and tubers & 555 & 87.5 \\
Good knowledge on legumes and nuts & 171 & 27.0 \\
Good knowledge on dairy products & 427 & 67.4 \\
Good knowledge on flesh foods & 169 & 26.7 \\
Good knowledge on eggs & 332 & 52.4 \\
Good knowledge on vitamin-A rich fruits and vegetables & 281 & 44.3 \\
Good knowledge on other fruits and vegetables & 290 & 45.7 \\
\hline
\end{tabular}

\subsection{Social influences to the mother on child feeding}

Concerning to the social influences of the mothers on infant and young child feeding, 108 (17\%) out of 634 mothers were influenced not to provide varieties of foods to their children. Peers were relatively high, $63(58.3 \%)$, followed by husbands in $23(21 \%)$ of the mothers, and the rest of nine, eight and five of the mothers were influenced by family members, relatives and neighbors, respectively.

\subsection{Dietary diversity practice}

The proportion of infants and young children who achieved the minimum requirement for dietary diversity was $160(25.2 \%$ with $95 \%$ CI: $21.9 \%, 28.8 \%)$ and mean score of 3.4 food groups. It was more practiced in males $(28.6 \%)$ than female children $(21.6 \%)$, and increased as the child age increases. Foods 
made from grains, cereals, roots and tubers were the highest, 555 (87.4\%), to be consumed by the children followed by dairy products which was consumed by $419(66 \%)$ of the children as shown in Table 3.

Table 3. Food Groups Consumed by Infants and Young Children Aged 6-23 in Haramaya Town of Eastern Ethiopia

\begin{tabular}{lcc}
\hline \multicolumn{1}{c}{ Food group } & Frequency & Percentage \\
\hline Grains, roots and tubers & 555 & 87.4 \\
Legumes and nuts & 159 & 25.0 \\
Dairy products & 419 & 66.0 \\
Flesh foods & 154 & 24.3 \\
Eggs & 326 & 51.3 \\
Vitamin-A rich fruits and vegetables & 275 & 43.3 \\
Other fruits and vegetables & 287 & 45.2 \\
\hline
\end{tabular}

\subsection{Factors associated with dietary diversity practice}

The study showed that mothers with educational status of secondary level and above were 2.97 times more likely [(AOR $=2.97,95 \% \mathrm{CI}:(1.26,6.99)]$ to practice dietary diversity than mothers who had no any formal education. Moreover, mothers who were working during one year prior to the study were 3.21 times more likely [(AOR=3.21, 95\% CI: $(1.41,7.29)]$ to achieve the minimum dietary diversity of their children compared to mothers who had no job. On the other hand, children whose age was 18-23 months old were 2.51 times more likely $(\mathrm{AOR}=2.51,95 \% \mathrm{CI}: 1.45,4.34)$ to achieve minimum dietary diversity compared to children aged 6-11 months. In addition, male children were 2.08 times more likely [( $\mathrm{AOR}=2.08$, 95\% CI: $(1.29,3.33)]$ to meet the minimum dietary diversity than female children. Children who were relatively healthy during two weeks prior to the study were 2.65 times more likely ( $\mathrm{AOR}=2.65,95 \% \mathrm{CI}$ : $1.36,5.16)$ achieve minimum dietary diversity compared to the sick children. Households in the richest quintiles were 4.45 times more likely [(AOR=4.45, $95 \%$ CI: $(1.94,10.22)]$ to meet the dietary diversity of their children as shown in Table 4.

\section{DISCUSSION}

The findings of this study assessed the magnitude (prevalence) and associated factors of dietary diversity practice among mothers of infant and young children aged 06-23 months in Haramaya town, eastern Ethiopia. Accordingly, the prevalence of dietary diversity in this study was $25.2 \%$ with a mean score of 3.4 food groups. It was practiced more in male children (28.6\%) than female children (21.6\%). It also increased as the age of the child increases.

The prevalence of dietary diversity in this study was about five times higher than the national figure of the country, Ethiopia [13]. However, the national report included many poor and remote rural areas, which might be the reason for the low prevalence at the national level. Similarly, the prevalence of dietary diversity in this study was found to be higher than other pocket studies conducted in northern Ethiopia in Enemay district (8.5\%), Abi-Adi (17\%) and Dangila (12.6\%) towns in 2013-2014 [14],[17],[18]. This might be due to differences in socioeconomic status and feeding habits.

The prevalence of dietary diversity in this study was almost consistent with studies conducted in southern Ethiopia in Kemba District (23.3\%) and Gamogofa zone (24.5\%) in 2012-2014 [16],[21]. However, it was lower than the study done in Shashemene district in 2014, which was 39.1\% [15]. This might be due to the district is closer to the capital city of the country, Addis Ababa, so that the physical accessibility of different food items is easy. Even though the prevalence of dietary diversity in this study was higher than most of the studies reported in Ethiopia, it was low as compared to other studies from outside of Ethiopia. It was lower than two studies conducted in Ghana in 2008 and 2012, which was $51.4 \%$ and 42\%, respectively [19],[22]. It was also much lower than a study done in Kenya (63.7\%) in 2010 [23]. This might be due to differences in scale of the studies (sample size), socio-economic status, and feeding habits.

The prevalence in the present study was also found to be lower than the studies conducted in China (45\%) in 2010 and Cambodia (44\%) in 2012 [24],[25]. Similarly, it was lower than three studies done in India in 2011-2014, which was $27.4 \%-47.8 \%$ [26]-[28]. This might be due to poor food production and consumption, and poor purchasing power of people in the study area for variety of foods. It might also be due to differences in scale of the studies (sample size). However, the prevalence was higher than a study done in Haiti (21\%) in 2013 [29]. This might be due to differences in socio-economic status and feeding habits.

The study revealed that mothers who learnt up to secondary level and above were about three times more likely to achieve the minimum standard for dietary diversity of their children compared to those who had no formal education. This was consistent with studies done in Nepal (2011), Sri-Lanka (2007), Indonesia

Dietary Diversity Practice and Associated Factors Among Infants and Young .... (Berhe Gebremichael) 
(2007), Nigeria (2013), Sierra-Leon (2008), three east African countries (Kenya, Uganda and Tanzania) (2008-2011), India (2006) and two studies from Ethiopia [14],[18], [30]-[35]. The possible explanation for this could be educated mothers are more likely to have more information, understand the education message, more likely to be engaged in paid work and might have received lessons on the child feeding in the curricula at school.

Table 4. Factors Associated with Dietary Diversity Practice Among Mothers of Infants and Young Children Aged 6-23 Months in the Haramaya Town of Eastern Ethiopia

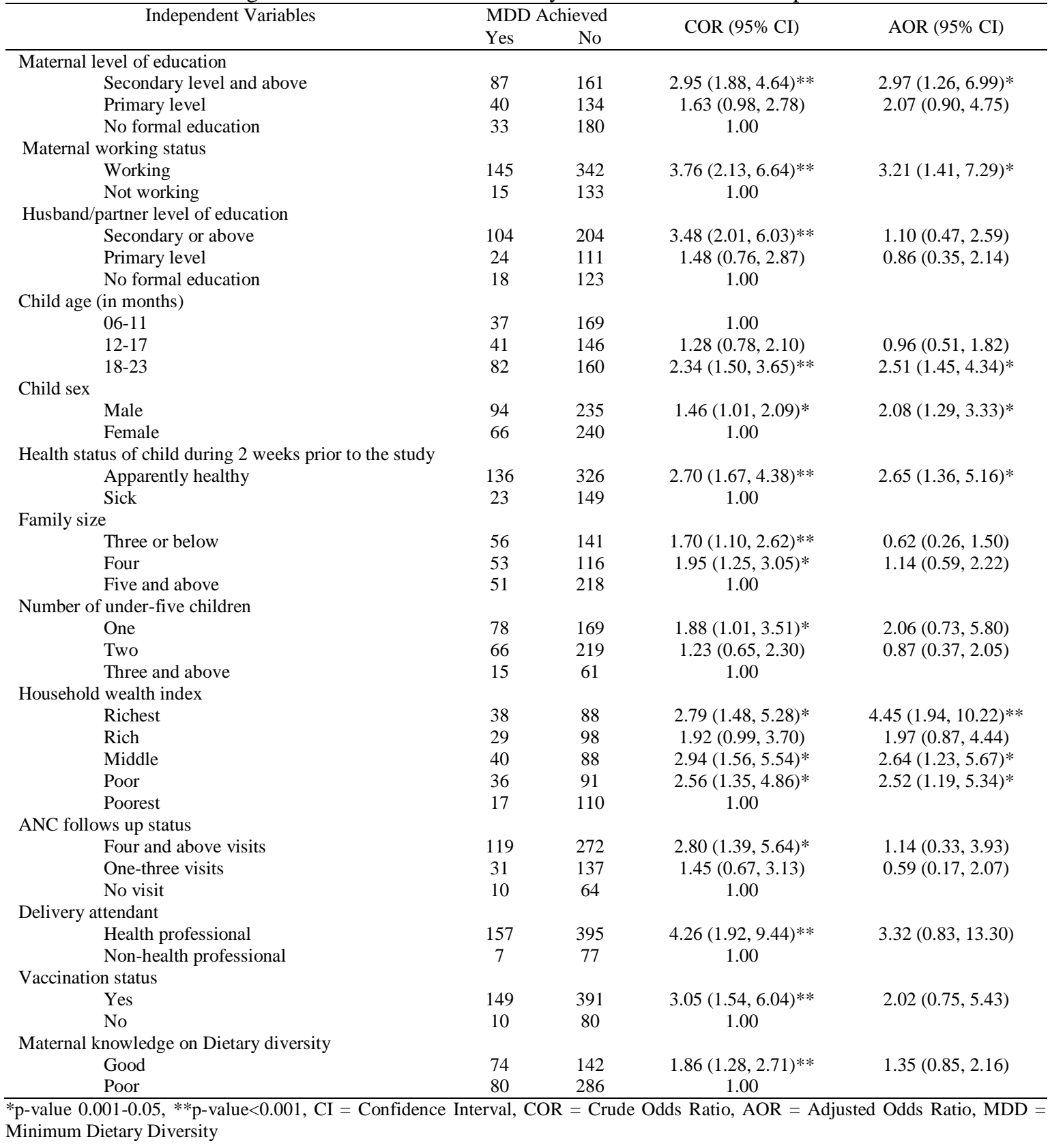

Likewise, this study showed that mothers who were working during one year prior to the study were 3.2 times more likely to practice dietary diversity of their children compared to those who were not working. This was similar with studies reported from Sierra-Leon (2008) and three east African countries (Kenya, Uganda and Tanzania) (2008-2011) [30],[31]. This could be explained as working mothers have their own income so that they can easily access and afford variety of foods for their children. 
According to this study, children whose age was 18-23 months were 2.5 times more likely to achieve minimum dietary diversity compared to those whose age was 6-11 months. This was consistent with studies done in Indonesia (2007), Sri-Lanka (2007), three East African countries (2008-2011) and Tanzania (2010) [30],[33],[35],[36]. This could be due to the late introduction of complementary feeding, mothers may perceive young child's intestine is not able to digest solid or semi-solid foods, and they may assume introducing bulky foods would lead children to develop infection.

The findings of the present study revealed that male children were 2.1 times more likely to meet minimum dietary diversity compared to female children. Beside of this, children who were relatively healthy two weeks prior to the study were about 2.7 times more likely to achieve minimum dietary diversity compared to those who were sick. This was in line with a study conducted in Liberia [31]. This might be due to poor consumption of variety of foods in sick children resulted from decreased appetite.

The study showed that richest households were 4.5 times more likely to meet the minimum dietary diversity standard for their children as compared to the poorest households. This was similar with studies done in India (2006), three east African countries (Kenya, Tanzania and Uganda) (2008-2011), Nigeria (2013), and Ethiopia (2011) [14],[18],[30],[31],[34]. This might be due to households with high wealth quintiles could easily access the food for their children thereby satisfying the dietary diversity.

\section{CONCLUSION}

One out of four mothers fed diversified diet adequately to their children, which needs critical concentration. Maternal level of education and work status, child age, sex and health status, and improved household's socioeconomic status were found to be positively associated with dietary diversity practice. Therefore, the health sector of the study site should disseminate messages on dietary diversity to mothers through health extension workers and different media. The health extension workers should also demonstrate for the mothers on how to prepare adequate diversified diet for their children. Moreover, the municipality of the study area should integrate with agricultural sectors to support households to grow cash crops to improve their economic status, as Ethiopia's economy is dependent on agriculture.

\section{ACKNOWLEDGEMENTS}

We would like to thank Haramaya University, College of Health and Medical Sciences, for supporting the primary author. Moreover, we would like to extend our heartfelt gratitude to the staffs of the Haramaya Town Health Office, Haramaya Town Municipality, Haramaya Hospital, and Haramaya Town health extension workers, data collectors, data collection supervisors, study participants, and questionnaire translators into the local languages.

\section{REFERENCES}

[1] P. Singer, et al., "What could infant and young child nutrition learn from sweatshops?" BMC Public Health, vol. 11 , pp. 276, 2011.

[2] WHO, UNICEF, "Strengthening action to improve feeding of infants and young children 6-23 months of age in nutrition and child health programmes," 2008.

[3] UNICEF, "Monitoring the Situation of Children and Women," 2015.

[4] WHO, "Indicators for assessing infant and young child feeding practices: Part 1: Definition," Geneva, The World Health Organization, 2008.

[5] WHO, "Children: reducing mortality," Geneva, World Health Organisation, 2014.

[6] R. E. Black, et al., "Maternal and child undernutrition: global and regional exposures and health consequences," Lancet, vol. 371, pp. 243-60, 2008.

[7] A. Imdad, et al., "Impact of maternal education about complementary feeding and provision of complementary foods on child growth in developing countries," BMC Public Health, vol/issue: 11(3), pp. 25, 2011.

[8] B. Daelmans, et al., "New and updated indicators for assessing infant and young child feeding," Food and Nutrition Bulletin, vol/issue: 30(2), pp. 256-62, 2009.

[9] C. K. Lutter, et al., "Undernutrition, poor feeding practices, and low coverage of key nutrition interventions," Pediatrics, vol. 128, pp. 6, 2011.

[10] K. Bezanson and P. Isenman, "Scaling up nutrition: a framework for action," Food and Nutrition Bulletin, vol. 31, pp. 178-86, 2010

[11] Z. A. Bhutta, et al., "What works? Interventions for maternal and child undernutrition and survival," Lancet, vol. 371, pp. 417-40, 2008.

[12] P. B. Marriott, et al., "World Health Organization (WHO) infant and young child feeding indicators: associations with growth measures in 14 low-income countries," Maternal and Child Nutrition, pp. 11, 2011.

[13] CSA, ICF, "Ethiopia Demographic and Health Survey 2011," Addis Ababa, Ethiopia and Calverton, Maryland, USA: Central Statistical Agency and ICF International., 2012. 
[14] M. Beyene, et al., "Dietary diversity, meal frequency and associated factors among infant and young children in Northwest Ethiopia: a cross- sectional study," BMC Public Health, vol/issue: 15(1007), pp. 1-9, 2015.

[15] F. Yonas, et al., "Infant and Young Child Feeding Practice Status and Associated Factors among Mothers of under 24-Month-Old Children in Shashemene Woreda, Oromia Region, Ethiopia," Open Access Library Journal, vol/issue: 2(1635), pp. 10, 2015.

[16] E. A. Gatahun and D. M. Abyu, "Dietary Diversity Feeding Practice and Determinants among Children Aged 6-23 Months in Kemba Woreda, Southern Ethiopia Implication for Public Health Intervention," Journal of Nutrition and Food Sciences, vol/issue: 13(13003), pp. 1-9, 2015.

[17] D. Gessese, et al., "The practice of complementary feeding and associated factors among mothers of children 6-23 months of age in Enemay district, Northwest Ethiopia," Journal of Nutrition and Food Science, vol/issue: 44(3), pp. 230-40, 2014.

[18] E. Mekbib, et al., "Magnitude and factors associated with appropriate complementary feeding among mothers having children 6-23 months-of-age in Northern Ethiopia; a community-based cross-sectional study," Journal of Food and Nutrition Sciences, vol/issue: 2(2), pp. 36-42, 2014.

[19] A. I. Issakaa, et al., "Determinants of inadequate complementary feeding practices among children aged 6-23 months in Ghana," Public Health Nutrition, vol/issue: 18(04), pp. 669-78, 2014.

[20] WHO, "Indicators for assessing infant and young child feeding practices: Part 2 Measurement," pp. 9, 2010.

[21] D. Tamiru and H. Jisha, "Dietary Patterns and Anthropometric Status of Under-Five Children in Arba Minch Zuria, Gamo Gofa Zone: Community-Based Cross-Sectional Study," Journal of Advances in Dairy Research, vol/issue: 3(2), 2015.

[22] S. Gyampoh, et al., "Child feeding knowledge and practices among women participating in growth monitoring and promotion in Accra, Ghana," BMC Pregnancy and Childbirth, vol/issue: 14(180), 2014.

[23] J. Kimiywe and P. M. Chege, "Complementary feeding practices and nutritional status of children 6-23 months in Kitui County, Kenya,” Journal of Applied Biosciences, vol. 85, pp. 7881- 90, 2015.

[24] A. Reinbott, et al., "A child feeding index is superior to WHO IYCF indicators in explaining length-for-age Zscores of young children in rural Cambodia," Paediatrics and International Child Health, vol/issue: 35(2), pp. 124$34,2015$.

[25] J. Sun, et al., "The nutritional status of young children and feeding practices two years after the Wenchuan Earthquake in the worst-affected areas in China," Asia Pacific Journal of Clinical Nutrition, vol/issue: 22(1), pp. 100-8, 2013.

[26] T. Mondal, et al., "Assessment of Infant and Young Child Feeding Practice among Tribal Women in Bhatar Block of Burdwan District in West Bengal, India," International Journal of Medical Science and Public Health, vol/issue: 3(3), pp. 324-6, 2014.

[27] K. Sonali, et al., "Infant and young child feeding practices among marginalized populations of Odisha, state in India," Journal of Epidemiological Research, vol/issue: 2(1), pp. 43, 2015.

[28] J. Swati, et al., "Assessment of Infant and Young Child Feeding Practices among Mothers in Rural Madhya Pradesh," National Journal of Community Medicine, vol/issue: 5(4), pp. 419-23, 2014.

[29] A. Laterra, et al., "Infant and young child feeding in four departments in Haiti: mixed-method study on prevalence of recommended practices and related attitudes, beliefs, and other determinants," Pan American Journal of Public Health, vol/issue: 36(5), pp. 306-13, 2014.

[30] C. A. Gewa and T. F. Leslie, "Distribution and determinants of young child feeding practices in the East African region: demographic health survey data analysis from 2008-2011," Journal of Health, Population and Nutrition, vol/issue: 34(6), 2015.

[31] A. I. Issaka, et al., "Determinants of suboptimal complementary feeding practices among children aged 6-23 months in four anglophone West African countries," Maternal and Child Nutrition, vol/issue: 11(1), pp. 14-30, 2015.

[32] V. Khanal, et al., "Determinants of complementary feeding practices among Nepalese children aged 6-23 months: findings from demographic and health survey 2011," BMC Pediatrics, vol. 13, pp. 131, 2013.

[33] C. S. Ng, et al., "Complementary feeding indicators and determinants of poor feeding practices in Indonesia: a secondary analysis of 2007 Demographic and Health Survey data," Public Health Nutrition, vol/issue: 15(5), pp. 827-39, 2011.

[34] A. Patel, et al., "Determinants of inappropriate complementary feeding practices in young children in India: secondary analysis of National Family Health Survey 2005-2006," Maternal and Child Nutrition, vol/issue: 8(1), pp. 28-44, 2012.

[35] U. Senarath, et al., "Determinants of inappropriate complementary feeding practices in young children in Sri Lanka: secondary data analysis of Demographic and Health Survey 2006-2007," Maternal and Child Nutrition, vol/issue: 8(1), pp. 60-77, 2012.

[36] R. Victor, et al., "Factors associated with inappropriate complementary feeding practices among children aged 6-23 months in Tanzania," Maternal and Child Nutrition, vol. 10, pp. 545-61, 2014. 